\title{
"CUANDO PASO POR TU PUERTA..." ANÁLISIS COMPARATISTA DE UN POEMA DE MIGUEL HERNÁNDEZ
}

Para Cristina

Entre marzo y septiembre de 1939, Miguel Hernández anotó, en la pequeña libreta que le acompañó en aquellos amargos días de cárcel, un conjunto de 74 poemas que componen el núcleo principal del que después sería su Cancionero y romancero de ausencias. Uno de sus más hermosos y emotivos poemas, el número 41 de la serie, no vería la letra impresa hasta 1961 (diecinueve años después de la muerte de su autor), sin título y sin la primera estrofa, que más adelante quedaría restaurada en esta versión más extensa del poema:

Cuando paso por tu puerta, la tarde me viene a herir con su hermosura desierta que no acaba de morir.

5

Tu puerta no tiene casa ni calle: tiene un camino por donde la tarde pasa como un caudaloso vino.

Tu puerta tiene una llave que para todos rechina. En la tarde hermosa y grave ni una sola golondrina.

En tu puerta no hay ventana por donde poderte hablar. Tarde, hermosura lejana que nunca podré lograr.

Hierbas en tu puerta crecen de ser apenas pisada. Todas las cosas padecen ante tu triste mirada. 
en la tarde azul de abierta.

25

Y la tarde azul corona

tu puerta gris, de vacía.

Y la noche se amontona

sin esperanzas de día ${ }^{1}$.

Entre la lectura del manuscrito principal del poema y las de otras fuentes manuscritas de Hernández pueden apreciarse variantes que afectan a los versos 8 (cuya alternativa sería "como un agua sin destino"), 18 ("de ser tan poco pisada") y 20 ("sobre la tarde abrasada"). La laguna más importante, la que figura entre los versos 21 y 23, quedaría "salvada" gracias a los siguientes versos, manuscritos en otros papeles del autor:

La piel de tu puerta encierra un lecho que compartir. La tarde no encuentra tierra donde ponerse a morir.

Lleno de un siglo de ocasos de una tarde azul de abierta, hundo en tu puerta mis pasos y no sales a tu puerta ${ }^{2}$.

\section{LA PUERTA Y LA TARDE}

Resulta más que obvio que, tras estas estremecidas cuartetas de Miguel Hernández, palpita la angustia de la separación de su esposa y el dolor de saberla absolutamente sola, indefensa y desatendida, sobre todo en lo emocional y en lo sentimental. El poeta, en efecto, se lamenta una y otra vez, más que de las precarias condiciones de vida en que ha debido quedar sumida su compañera, de la soledad y el abandono amorosos que deben atenazarla, simbolizados en el vacío del "lecho que compartir" al que tiene que enfrentarse cada día mientras su esposo la recuerda impotente desde la prisión:

${ }^{1}$ Desecho la primera edición del poema, publicado en diciembre de 1961 en los Papeles de Son Armadans, 69, y sigo la versión más completa y crítica publicada en Miguel Hernández, El hombre acecha. Cancionero y romancero de ausencias, eds. L. de Luis y J. Urrutia, Cátedra, Madrid, 1988, pp. 185-186.

2 Véanse las notas de la ed. cit. de L. de Luis y J. Urrutia. 
La piel de tu puerta encierra un lecho que compartir.

La tarde no encuentra tierra donde ponerse a morir.

No cabe duda de que la palabra puerta, sobre la que se levanta toda la arquitectura simbólica del poema de Miguel Hernández, opera aquí como una especie de metáfora amorosa, e incluso sexual, que identificaría a un tiempo las zonas eróticas del propio cuerpo - "la piel de tu puerta..."-y los impulsos, deseos y frustraciones amorosos de la mujer separada a la fuerza de su marido. Y que la palabra tarde, presente también en todas las estrofas del poema (excepto en la quinta), constituye una compañera simbólica perfecta, con su inevitable carga connotativa relacionada con el ocaso y con la oscuridad, de la puerta abandonada y cerrada a los luminosos goces del amor.

Resulta impresionante constatar las estrategias verbales y simbólicas -basadas en el uso de la negación omnipresente en el plano formal y en el del contenido del poema-que utiliza Miguel Hernández para lamentar, a un tiempo, la falta de satisfacción amorosa y de esperanzadora luz que aqueja a los dos amantes. En sus escasas y concentradas cuartetas, la puerta de la mujer "no tiene casa", en ella "no hay ventana", es apenas pisada, la puerta es "gris, de vacía", tiene "un lecho que compartir", y la mujer nunca sale "a tu puerta"; por su parte, la tarde tiene "una hermosura desierta", "no acaba de morir", no tiene "ni una sola golondrina", tiene una "hermosura lejana / que nunca podré lograr", está "sin esperanzas de día”, "no encuentra tierra / donde ponerse a morir", y se identifica con "un siglo de ocasos".

La forzosa insatisfacción de los deseos amorosos y la angustiosa falta de esperanza, vertidas en la metáfora de la imposibilidad de entrar por la puerta de la mujer para que la tarde se llene de luz, encuentran, en los versos de Miguel Hernández, una formulación de coherencia formal - por medio de las negaciones léxicas y sintácticas-y de profundidad simbólica - gracias a las metáforas relacionadas con la puerta no transitada y con la tarde moribunda- tan compactas y emotivas que sería difícil encontrar, en lengua española, poemas capaces de transmitir sentimientos de desolación tan intensos y lacerantes como los que comunica éste.

\section{LA PUERTA Y EL SEXO FEMENINO}

La interpretación del poema de Miguel Hernández podrá enriquecerse notablemente si lo ponemos en relación con una vieja y arraigadísima tradición, casi universal, que equipara la voz y el significado de la puerta con el sexo femenino. 
Un reciente y agudo estudio de Louise O. Vasvari sobre el simbolismo sexual femenino de las puertas ${ }^{3}$ nos exime ahora de acumular demasiados detalles al respecto. Baste decir que Vasvari parte de un célebre romance castellano documentado en los siglos XV y XVI, el que comenzaba "Yo me era mora Moraima" o "moraina", para afirmar que la escena en que la mora abre la puerta al falso cristiano disfrazado de moro - tradicionalmente interpretada como la descripción de una violación- no es más que una pura metáfora de una relación amorosa consentida entre una mujer - que viste con toda intención sólo un ligero "almejí no hallando mi brial"- y abre su puerta - sexual-al hombre que la galantea:

Yo m'era mora Moraima, morilla d'un bel catar; cristiano vino a mi puerta, cuitada, por m'engañar; hablóme en algaravía como aquel que la bien sabe: -Ábrasme las puertas, mora, si Alá te guarde de mal. -¿Cómo t’abriré, mezquina, que no sé quién te serás? -Yo soy el moro Mazote, hermano de la tu madre, que un cristiano dejo muerto, tras de mí viene el alcaide.

Si no me abres tú, mi vida, aquí me verás matar-. Cuando esto oí, cuitada, comencéme a levantar; vistiérame un almejí no hallando mi brial; fuérame para la puerta y abríla de par en par ${ }^{4}$.

Vasvari avala la interpretación erótica de este poema, y las connotaciones genitales de la palabra puerta, aduciendo docenas de textos de innumerables tradiciones literarias y folclóricas de todo el mundo -desde el Cantar de los cantares bíblico hasta hoy- que muestran los obvios paralelismos entre esa voz y la designación eufemística del sexo femenino.

Para no caer en reiteraciones superfluas, traeremos ahora a colación sólo textos que no fueron comentados en el trabajo de Vasvari. Partiremos del Poema de Gilgamesh, escrito en lengua acadia en la Babilonia de antes de 1500 a.C, y que presenta el momento en que el héroe rechaza así la seducción de la diosa Ishtar:

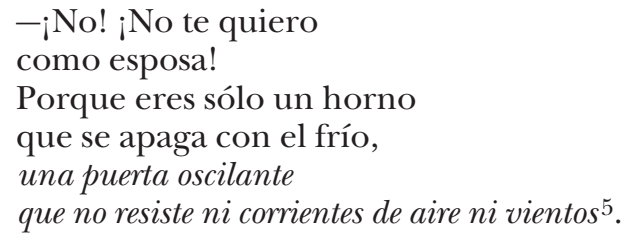

3 The heterotextual body of the "Mora morilla", Queen Mary and Westfield College, London, 1999.

${ }^{4}$ Sigo la versión del Romancero, ed. Paloma Díaz-Mas, Crítica, Barcelona, 1994, núm. 83.

${ }^{5}$ La epopeya de Gilgamesh, el gran hombre que no quería morir, ed. J. Bottéro, trad. P. 
En el medieval Cantar de Guillermo francés, la escena del regreso del protagonista a su hogar tiene una fuerte connotación erótica, reforzada por la irónica alusión "al bulto de la nariz" que la esposa pretende reconocer antes de franquear sus puertas al forastero:

El noble conde llega hasta la ciudad:

-iGuiburc! ¿Me dejaréis entrar?

-No - dice ella-, por la fe que debo a Dios, si no me mostráis el bulto de la nariz que tenía Guillermo, el marqués de la nariz corva, después de la batalla contra el rey Teobaldo el Eslavo. Muchos hombres se parecen por el valor y la nobleza, pero yo estoy sola, ningún hombre hay a mi lado excepto el portero que aquí veis.

Entonces el conde dice:

-iJamás escuché palabras tales! Este adversario me ha hecho sufrir hoy mucho.

Desata los lazos de su yelmo engastado con piedras preciosas y lo deja deslizar sobre sus hombros y toda la cara queda al descubierto. La dama lo mira y lo reconoce perfectamente; lanza un profundo suspiro y comienza a llorar de los ojos:

-Amigo mío, hermano querido, abridle, pues es Guillermo, mi señor legítimo.

Lunes al anochecer.

Abren la puerta y reciben a Guillermo. Hace mucho tiempo que deseaba estar dentro ${ }^{6}$.

¿Cómo no apreciar en este curiosísimo bulto de la nariz de Guillermo un eufemismo fálico similar -hasta en su ironía- al que resulta también reconocible en el pie helado del poema latino medieval que decía

Tanto tiempo, señora, he merodeado junto a tu puerta, que mi pie está helado, hermosa señora, por tu amor, atado a la estaca?

En el Cancionero de obras de burlas provocantes a risas de comienzos del siglo xvI, una célebre prostituta era presentada en los siguientes términos:

Gracia es una mujer enamorada, gran labrandera... Es mujer que continuo está en su puerta labrando y por maravilla passa ninguno que ella no

López Barja de Quiroga, Akal, Madrid, 1998, p. 146. Sobre el simbolismo erótico de la voz horno, presente también en estos versos, véase mi artículo "El herrero, las cabrillas y el horno: léxico y simbolismo eróticos en La Lozana Andaluza (XIV) y el Quijote (II: 41)", Criticón, en prensa.

${ }^{6}$ Cantar de Guillermo, ed. J. Rubio Tovar, Gredos, Madrid, 1997, pp. 153-154.

7 Peter Dronke, La lírica en la Edad Media, Ariel, Barcelona, 1995, p. 185. 
lo mire... Agora es amiga de un sastre y tiene también algunos girones eclesiásticos...8.

En las siguientes cancioncillas folclóricas se podrá advertir también la amplia variedad de registros con que puede sustanciarse el paralelismo simbólico entre la puerta y el sexo femenino:

\author{
Ábreme la puerta, \\ la puerta de la calle, \\ que esta noche vengo \\ a hablar con tu padre ${ }^{9}$. \\ Si tu madre no quiere \\ que te visite, \\ que te tape la puerta \\ con un tabique ${ }^{10}$. \\ Abre la puerta, María, \\ que te traigo el aguinaldo: \\ una morcilla caliente. \\ ¡Aprieta, que salga el caldo ${ }^{11}$ ! \\ Al pasar por tu puerta \\ te vi las bragas, \\ y como eran encarnadas \\ se me espantó el macho' ${ }^{12}$.
}

Que el sentido erótico de la voz puerta se ha mantenido vivo hasta hoy lo avalan, finalmente, dos escenas muy reveladoras de una re-

${ }^{8}$ Eds. J. A. Bellón y P. Jauralde Pou, Akal, Madrid, 1974, p. 188. Sobre el sentido erótico y la relación con la prostitución del adjetivo "labrandera", véanse MANUEL DA Costa Fontes, "Celestina’s hilado and related symbols", Cel, 1984, núm. 8, 3-13 y "Celestina's hilado and related symbols: A supplement", Cel, 1985, núm. 9, 33-38; IAN MacPherson, "Celestina labrandera", RLitMed, 4 (1992), 177-186; e I. MaCPHERSON y Angus MackaY, "Manteniendo la tela: el erotismo del vocabulario caballeresco-textil en la época de los Reyes Católicos", en Actas del Primer Congreso Anglo-Hispano, t. 2: Literatura, eds. A. Deyermond y R. Penny, Castalia, Madrid, 1993, pp. 25-36.

${ }^{9}$ Domingo Hergueta y Martín, Folklore burgalés, Diputación Provincial, Burgos, 1934 [reimp. 1989], p. 93; reproducido en Ignacio FernándeZ de Mata, De la vida, del amor y la muerte. Burgos y su provincia en la Encuesta de 1901-1902 del Ateneo de Madrid, Librería Berceo, Berceo, 1997, p. 76.

${ }^{10}$ Manuel Urbano, Sal gorda: cantares picantes del folklore español, Hiperión, Madrid, 1999, p. 81.

${ }^{11}$ Ibid., p. 180.

12 Canción comunicada por Vicente Sánchez, nacido en Tobarra (Albacete) en 1955, y entrevistado por mí en Madrid el 11 de marzo de 1992. 
ciente novela del escritor y cineasta chileno Miguel Littin, El bandido de los ojos transparentes. La primera es abiertamente erótica:

Me monté encima de ella, y abriéndole las piernas cerré los ojos y entré en su casa sin golpear la puerta. Entre sueños abrió sus ojos verdes y me ofreció su boca... ${ }^{13}$.

El erotismo de la segunda escena resulta mucho más velado, aunque sigue siendo inconfundible. Presenta al protagonista, el bandido El Torito convertido en apacible zapatero, celosamente vigilado por su mujer a partir del momento en que dos jóvenes forasteras, recién llegadas al pueblo, se dedican a excitar los instintos libidinosos a través de su puerta:

-Mañana va a cerrar la puerta.

- ¿Y cómo quiere que trabaje sin luz, señora Feliciana?

-Prenda la lámpara de carburo - contestó ella, y me sirvió otro mate.

Lo de la lámpara me recordó la cárcel, pero no dije nada, porque como la Feliciana nada sabía de esa parte de mi vida, no era tampoco el momento de hablar de cosas del pasado.

-Prende bien la lámpara de carburo, que da mucha y buena viva luz de noche, hasta que se vayan del pueblo esas forasteras, tan inquietas y fijonas. Nada de mirar tanto a la calle, porque me lo ojean ${ }^{14}$.

"Tu PUERTA TIENE UnA LlaVe / QUE PARA TODOS REChINA..."

Una vez constatadas la ambivalencia significativa de la palabra puerta y sus posibilidades de connotación erótica, resulta mucho más inteligible la interpretación de estrofas del poema de Hernández como la que decía

Tu puerta tiene una llave que para todos rechina.

En la tarde hermosa y grave ni una sola golondrina.

La imposibilidad de que ninguna llave abra la puerta de la mujer mientras el marido está en prisión, expresada en los versos desolados del poeta alicantino, nos vuelve a enfrentar a otra metáfora erótica bien atestiguada desde tiempos muy antiguos: la de la llave, que ha contado con un tradicional sentido fálico muchas veces contrapuesto al femenino de la puerta.

${ }^{13}$ Seix Barral, Barcelona, 1999, p. 167.

14 Ibid., p. 175. 
Una vez más, Vasvari ha traído a colación, al respecto, una estrofa lírica latina que forma parte de las conocidas como Canciones de Cambridge de los siglos XI-XIII:

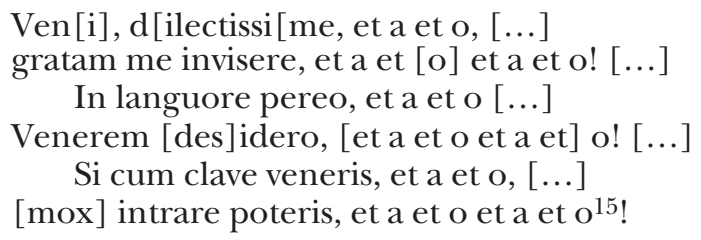

Es decir:

Ven, mi amor... visítame; me complace... Me muero por la distancia... Deseo hacer el amor... Si vienes con tu llave... podrás entrar rápidamente...

Otra canción inglesa, en este caso la folclórica Strawberry fair, evocada también por Vasvari, decía así:

Oh, I have a lock that doth lack a key, ritol, ritol, riddletol delido,

I have a lock that doth lack a key, Tol de dee,

I have a lock, sir', she did say, and if you got the key then come this way, Ritol, ritol, riddletol de lido ${ }^{16}$.

Es decir:

Oh, yo tengo un cerrojo al que le falta la llave... Yo tengo un cerrojo al que le falta la llave... Yo tengo un cerrojo, señor, dijo ella, y si usted tiene la llave, véngase por aquí...

Además de las muy sugerentes canciones folclóricas españolas - que no vamos a reproducir-aducidas por Vasvari, se pueden aducir otras que terminan de demostrar el innegable simbolismo fálico de la palabra llave en el contexto de los versos de Miguel Hernández:

Contigo no quieo más liga;

mi puerta no gasta yabe

de media noche $p$ 'arriba $^{17}$.

15 Op. cit., p. 80. Muchos más datos sobre el simbolismo fálico de la llave se podrán encontrar en las pp. 80-81.

${ }^{16}$ Ibid., p. 80.

${ }^{17}$ Francisco Rodríguez Marín, Cantos populares españoles, 4 ts., Francisco Álvarez y Cía., Sevilla, 1882-1883, núm. 4797. 
Como mucho está lloviendo

y la noche está obscura, a tientas te estoy metiendo

la llave en la cerradura.

Tienes el baúl abierto y ni Dios sabe

si te lo habrán abierto con una llave.

Si te lo habrán abierto; y ¡olé lo bueno!,

lo que tiene mi abuela es $p a$ mi abuelo ${ }^{18}$.

"Hierbas En tu PUerta CRECEN / DE SER APENAS PISADA..."

Dentro de la apretadísima constelación simbólica del poema amoroso de Miguel Hernández, que hace girar en torno a la imagen omnipresente de la puerta otras metáforas secundarias como la de la llave, pueden aún rastrearse más elementos de simbolismo tan sutil y profundo como respaldado por añejas tradiciones.

Por ejemplo, si atendemos a la quinta cuarteta del poema, la que afirma que

Hierbas en tu puerta crecen

de ser apenas pisada.

20

Todas las cosas padecen ante tu triste mirada,

que, con las variantes de los otros manuscritos podría leerse también

Hierbas en tu puerta crecen

de ser tan poco pisada.

Todas las cosas padecen

20 sobre la tierra abrasada,

no nos será difícil llegar a la conclusión de que estamos ante una lamentación, apenas velada, de la forzosa inactividad sexual a que la reclusión del hombre condena al matrimonio.

La expresión pisar tiene efectivamente, y desde muy antiguo, una acepción indudablemente erótica, muy posiblemente relacionada con ciertos ritos de galanteo y de matrimonio que se hallan bien documentados en la Edad Media europea:

18 M. Urbano, op. cit., p. 208. 
La entrega de la novia al novio iba seguida de la toma de posesión por parte de éste, expresada en el gesto de pisarle el pie o entregarle un zapato o una zapatilla. El nombre alemán del marido condescendiente, Pantoffelheld, "héroe de la zapatilla", expresa todavía hoy una relación matrimonial invertida. Con este acto concluían los esponsales ${ }^{19}$.

Hasta hoy han llegado ecos de este tipo de creencias y de rituales, como los que se siguen practicando en el santuario navarro de San Gregorio Ostiense:

Iban a San Gregorio Ostiense. Si pisas el ladrillo, te casas en un año. Fuimos una panda de nosotras, y fue una mayor, y se casó. ¡[Eso sucedió] dos veces ${ }^{20 !}$

En cualquier caso, la acepción erótica de pisar ha quedado muy bien documentada en el léxico y en la literatura española, empezando por uno de los más célebres Milagros de Nuestra Señora de Gonzalo de Berceo, el que, al relatar De cómo una abbadesa fue prennada et por su conbento fue acusada et despues por la Virgen librada, presentaba esta escena:
Pero la abbadessa cadió una vegada, hizo una locura que es mucho vedada; pisó por su ventura yerva fuert enconada, quando bien se catido fallóse embargada ${ }^{21}$.

La documentación, a partir de la Edad Media, del verbo pisar, y especialmente de pisar hierba-recuérdese que los versos de Miguel Hernández decían "Hierbas en tu puerta crecen / de ser apenas pisada..."- con sentido erótico ha sido muy abundante, y ha dejado un rastro muy apreciable en el cancionero y en el romancero de todo el mundo hispánico, además de en la literatura culta de inspiración popular $^{22}$. Véanse, por ejemplo, las siguientes cancioncillas folclóricas:
Dámelo, bella mujer, dámelo una vez siquiera, te lo dejo de manera que no se manche tu honor.

19 Peter Blicke, "En evidente perjuicio del bien común: las bodas campesinas en la Edad Media”, en La fiesta: una historia cultural desde la Antigüedad hasta nuestros días, ed. Uwe Schultz, trad. José Luis Gil-Aristu, Altaya, Madrid, 1998, p. 127.

${ }^{20}$ La informante María Socorro Vidán, nacida en 1932 en Ganuza (Navarra) fue entrevistada por mí en su pueblo en agosto de 1995, en una encuesta realizada junto con Alfredo Asiain Ansorena y Mariola Roa.

21 Gonzalo de Berceo, Milagros de Nuestra Señora, ed. M. Gerli, Cátedra, Madrid, 1992, p. 157, núm. XXI, est. 507, p. 157.

${ }^{22}$ Véanse numerosos ejemplos en Daniel Devoto, "Pisó yerba enconada", Textos y contextos, Gredos, Madrid, 1974, pp. 11-46, esp. pp. 31-41. 
Déjame pisar la flor

que el hombre tanto venera, que no se manche tu honor, déjame pulsiar la flor que el hombre tanto venera ${ }^{23}$.

-¡Ay! Niña, que te lo piso, niña que te piso el pie!

-No quiero que me lo pises, mira que me va a doler ${ }^{24}$.

Una moza bailando se la miraba, la punta del zapato que le apretaba; eso sería que el bailador, bailando la pisaría ${ }^{25}$.

La niña bonita no tiene parné porque los soldados le pisan el pie... ${ }^{26}$

Un ejemplo muchas veces citado de la perífrasis pisar hierba con sentido sexual es el del romance de La doncella parida, que, en una versión del pueblo de Navarrevisca (Ávila), decía así:

En el jardín del amor hay una flor encarnada, la doncella que la pise ha de ser muy desgraciada; quiso Dios, quiso la Virgen, de que Eugenia la pisara, y un día estando a la mesa, su padre la remiraba.

-¿Qué me mira usté, mi padre, qué me mira usté a la cara?

-Hija, que tú estás enferma, o es que estás enamorada.

-Padre, yo no estoy enferma, ni tampoco enamorada, tengo un dolor de cabeza que hasta el alma me traspasa. Se ha metido en su habitación, donde cosía y bordaba, y entre dolor y dolor, y entre puntada y puntada,

23 Manuel J. Lorenzo Perera, El folklore de la Isla de El Hierro, Editorial Interinsular Canaria-Excmo. Cabildo Insular, El Hierro, 1981, p. 199.

24 Ángela Capdevielle, Cancionero de Cáceres y su provincia, Diputación Provincial, Cáceres, 1969, p. 47.

25 José Manuel Fernández Cano, Mil cantares populares, Diputación, Ciudad Real, 1998, núm. 915.

${ }^{26}$ Antonio Vallejo Cisneros, Música y tradiciones populares, Diputación, Ciudad Real, 1988, p. 104. 
y al cabo de las dos horas, una clavelina blanca.

-Se la lleva usted, don Juan, envueltecita en la capa, que si mi padre se entera, la cabeza le cortara.

Al bajar las escaleras, con el resuello de cara, [se encuentra a]

-¿Qué llevas ahí, envueltecita en la capa?

-Llevo rosas y jazmines, que las corté de mañana ${ }^{27}$.

Si la expresión pisar la hierba tiene, en tantos textos, la connotación de "tener trato sexual", el sentido de los versos de Miguel Hernández

Hierbas en tu puerta crecen

de ser apenas pisada...

no puede dejar de revelarse como una lamentación, llena de frustración y amargura, de la forzada inactividad sexual a la que se ve irremediablemente condenada la esposa del hombre preso.

Otra cancioncilla popular que alude a "la mala hierba [que] ha crecido" en el hogar de una mujer separada de su esposo refuerza esta interpretación:

Desde que te fuiste, Pedro,

el huerto no se ha regado,

la mala hierba ha crecido,

el perejil se ha secado ${ }^{28}$.

Para comprender aún mejor el tejido metafórico de los versos de Miguel Hernández, merece la pena conocer dos seguidillas anónimas del siglo XvII que vuelven a mostrar la identificación de lo femenino con la hierba que espera la llegada del varón:

Hortelano del alma, regá la güerta, que se me abraso toda de puro seca.

${ }^{27}$ La informante fue una mujer de 77 años, de Navarrevisca (Ávila), entrevistada por mí en Villanueva de Ávila en julio de 1996.

28 Fernando Gomarín Guirado, Cancionero secreto de Cantabria, Universidad de Cantabria, Santander, 1989, núm. 163. Véanse además las variantes publicadas en Fernández Cano, Mil cantares populares, núm. 78: "Desde que te fuiste, Pepe, / el huerto no se ha regado, / la hierbabuena se seca, / y el perejil se ha secado"; y en Urbano, op. cit., p. 142: "Desde que te fuiste, Pepe, / el huerto no se ha regao, / la hierbabuena no crece / y el perejil se ha secao". 
Hortelano del alma, ande la noria, que de seca se me abre la güerta toda ${ }^{29}$.

Para concluir, vamos a conocer otras dos cancioncillas populares que establecen paralelos entre el acto amoroso y la siembra de una planta por parte del hombre en la puerta de la mujer. A su luz, el poema de Miguel Hernández termina de revelársenos no sólo como uno de los más profundos e intensos de toda la poesía amorosa española, sino también como uno de los que de forma más consciente, elaborada y perfecta han sabido insertarse dentro de una tradición de símbolos y metáforas literarias que muy pocos poetas han podido manejar con la maestría y la sensibilidad del poeta alicantino:

A tu puerta puse un pino,

a tu ventana un cerezo, por cada guinda un abrazo, por cada abrazo un beso ${ }^{30}$.

En tu puerta sembré un pino en tu ventana una flor, en tu pecho dos claveles y en tu corazón mi amor ${ }^{31}$.

José Manuel Pedrosa

Universidad de Alcalá

29 Kenneth Brown, "Doscientas cuarenta seguidillas antiguas", Criticón, 1995, núm. 63, 7-27, núms. 64-65.

${ }^{30}$ Simón Guadalajara Solera, Lo pastoril en la cultura extremeña, Institución Cultural "El Brocense", Cáceres, 1984, p. 165.

31 IsABel BARAHONa, "Transcripción del trabajo de campo", en Literatura tradicional sin fronteras: el repertorio multicultural de Montreal, ed. J. M. Pedrosa, Montreal, 1997, p. 26. 